\title{
NOVAS TECNOLOGIAS PARA QUE?
}

\author{
Suzanna Sochaczewski*
}

a ust in Time Kanban, robôse máquinas de controle numérico, células e ilhas de produção, polivalência, terceirização, automação, defeito zero, CCQ. CEP, TPM, TQC... Cada vez mais. essas palavras e siglas estranhas fazem parte do cotidiano do trabalhador. São os nomes dados àsnovas tecnologiaseàs novas formas de organização e gestão da produção e do trabalho. Até algum tempoatrás, essas novidades estavam restritas a alguns setores $\mathrm{cm}$ países desenvolvidos. Hoje, estão em toda a parte, modificando a maneira de produzir bens e serviços, mexendo com o trabalho e a vida das pessoas.

Embora mereçam a qualificação de novas, porque representam de fatouma revolução no modo como se fabrica alguma coisa ou se prestaum serviço, não se pode esquecer que as atuais inovaçõcs fazem partc de uma longa sucessão de novas tecnologias. Desde sempre, ohomem vem inventando. transformando, revolucionando sua forma de trabalhar. A história mostra que, nas diferentes sociedades, e ao longodo tempo, vão mudando as ferramentas, as máquinas, os equipamentos, a maneira de organizar a produção. de atribuir tarefas e responsabilidades e de distribuir os frutos do trabalho.

É um caminho que percorre muitas etapas. Para transportar o produto de scu trabalho. por exemplo, os homens foram inventando, e acrescentandoà própria força física. cordas, alavancas, guindastes. carretas, trens, caminhões, aviões, em um longo processo até chegar aos terminais de containers de hoje. Se pensarmos na prática da medicina. que sempre acompanhou o homem, vemos como cla foi deixando de ser a intervenção e dádiva dos deuses dos primórdios da humanidade para se tornar uma ciência de especialistas com recursos técnicos incríveis usando até computadores e raios laser. Ou scja, a história da humanidade é também a história. cada vez mais sofisticada, de transformação da natureza.

Isso não significa, entrctanto, que se deixou deusar a força física ou que não exista mais trabalho pesado ou perigoso. As sociedades humanas têm se caracterizado pela convivência do novo com ovelho. Embora as invenções tenham como objetivo facilitar e poupar trabalho, chegando no limite ao fim de todo o trabalho compulsório, o uso que delas se fez, e se faz. foi sendo determinado pcla forma de organização social, pela relação de força e pelo poder de intervenção c interesses dos diferentes grupos $\mathrm{cm}$ cada sociedade.

Assim sendo, surge a pergunta: hoje, no Brasil, do ponto de vista dos trabalhadores, novas tecnologias para que?

Para produzir mais, melhor, com menos trabalho e mais riqueza para todos? $\mathrm{Nem}$ sempre tem sidoesse odestino das invenções e descobertas da humanidade. Em muitas sociedades o resultado foi. pelo contrário. 0 acúmulo de riquezas para alguns e pouca diferença para melhor para a grande maioria.

Nos últimos quinhentos anos, o capitalismo foi acelcrando o ritmo de mudanças com a utilização crescente de novas tecnologias. A manufatura organizada de forma capitalista e em scguida a produção industrial revolucionaram técnicas, métodos, instrumentos e máquinas, possibilitando a criação de uma riqueza, até então. inćdita no mundo $\mathrm{cm}$ termos de diversidade e quantidade de produtos.

Infelizmente, as pessoas comuns têm usufruído muito pouco dessa abundância. A história da maior parte dos trabalhadores, homens, mulheres ou crianças, retrata muito mais a luta pela sobrevivênciaqueogozo da riqueza criada com o seu trabalho.

A cada etapa tecnológica da história capitalista, os trabalhadores têm enfrentado novas condições de trabalho, sempre impostas como se fossem as únicas possíveis. Em alguns momentos, é preciso lutar contra formas, especialmente. desumanas de trabalho como. por exemplo. quando scus filhos são incorporados à produção pela necessidade de sobrevivência e pela lógica capitalista que não se envergonha de explorar o trabalho de crianças. Cada um dos direitos hoje vigentes - a jornada regulamentada, as horas extras pagas. o descanso remunerado, as férias. a aposentadoria, a proibição do trabalho infantil - foram possibilidade mas não resultado do progresso técnico e tiveram que ser conquistados, e reconquistados, através de uma luta que dura séculos. Assim, embora cada novo patamar tecnológico signifique benefícios materiais importantes, estesnão sãoautomaticamente compartilhados por todos.

Hoje, mais uma vez, os trabalhadores se defrontam com uma revolução na forma de produzir bens e serviços. Segundo alguns, é a maior revolução de todos os tempos.

A reestruturação produtiva em curso, com a introdução de equipamentos microeletrônicos e mudanças radicais de organização gestão do trabalho e da produ-

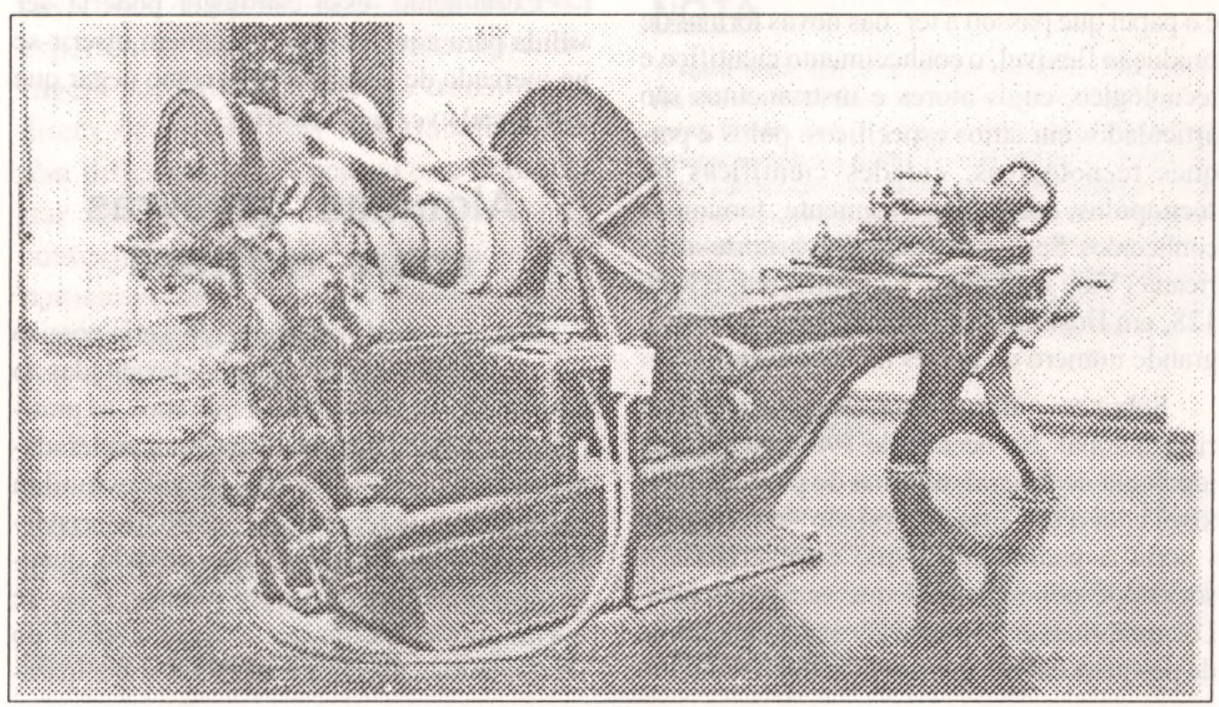

Foto: Cutti 
ção, encontra os trabalhadores esperançosos, por um lado, com as possibilidades abertas por um aumento extraordinário da produtividadee temerosos, por outro. com as consequências nefastas que o mesmo processo pode acarretar.

No Brasil, há mais ou menos dez anos, sindicatos, comissões de fábrica, o Diecse $\mathrm{c}$. mais recentemente, as Centrais Sindicais vêm estudando, discutindo e negociando a introdução de inovações tecnológicas. Ofato das chamadas novas tecnologias fazerem parte do cotidiano de fábricas eescritórios dá aos trabalhadores conhecimento e autoridade para se pronunciar sobre seus efeitos no trabalho e na sociedade.

Essa reflexão e essa luta em torno desta questão estão presentes em inúmeros documentos sindicais - resoluções de congressos, relatórios de seminários, estudos especiais, pautas de reivindicação - que mostram o ponto de vista próprio dos trabalhadores nessa questão.

Longe de se opor ao avanço tecnológico, os trabalhadores o vêem como fruto do exercício do trabalhoe patrimônio da humanidade. Estabelecem, entretanto, condições e apontam pré-requisitos para que as novas tecnologias possam trazer benefícios para todos. Em primeiro lugar, reivindicam que os ganhos de produtividade devem ser compartilhados por toda a sociedade através de aumentos reais de salários e diminuição dos preços de produtos e serviços.

Além disso, na medida que a adoção de novas tecnologias reduz o númcro de postos de trabalho em muitas áreas, faz-se necessária uma política de pleno emprego, diminu- indo não só a jornada diária mas também o tempo de vida dedicado ao trabalho, adiando a entrada de criançase jovens no mercado de trabalho epossibilitando uma aposentadoria recompensadora. Essa política deve conter. ao mesmo tempo, programas de requalificação profissional que permitam realocar parte daqueles dispensados pela reestruturação produtiva. Finalmente. consideram importante negociaruma moratória tecnológica, a exemplo de outros países, que permita aos trabalhadores um processo de transição em condições dignas.

Para os trabalhadores, novastecnologias servem para eliminar trabalho pesado, insalubre e perigoso, ou scja, essas devem ser as prioridades para a reestruturação. Além disso, devem estar destinadas à elevação das condições de vida com educação e saúde de boa qualidade e moradia, transporte e infraestrutura condizentes com o avanço tecnológico alcançado.

Finalmente, como partediretamenteafetada pelo progresso técnico, seja como trabalhadores, seja como consumidores, reivindicam sua participação no processo, desde em discussões ao nível das empresas, até $\mathrm{em}$ órgãos que formulam políticas de Ciência e Tecnologia.

É importante ressaltar que a perspectiva de progresso tecnológico dos trabalhadores está indissoluvelmente ligada à qualidade de vida que inclui e extrapola o processo e o local de trabalho. Não faz sentido, desde o seu ponto de vista, utilizar o que existe de mais moderno para trabalhar - os bancários, por exemplo, convivem, no seu dia-a-dia, com as últimas novidades elctrônicas - $\mathrm{e}$, ao mesmo tempo, estar preso a condições de

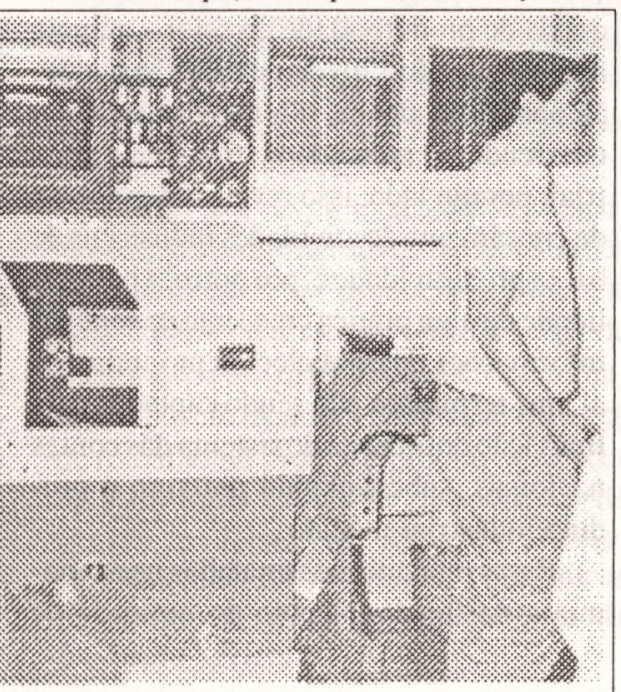

trabalho e de vida que parecem pertencer a outro lugar e a outro tempo.

Isso responde à pergunta novas tecnologias para que? Os trabalhadores querem viver melhor. o que nem sempre coincide com os objetivos que estão por trás da implantação de inovações tecnológicas. É por esse motivo que se impõe a negociação das formas e ritmos de implantação, das políticas e prioridades e da escolha dos bencficiários.

Embora essas questões ainda não estejam rcsolvidas, e no Brasil sua discussão seja incipiente e localizada, a atual recstruturação produtiva traz consigo uma mudança qualitativa inćdita no longo caminho percorrido pelos homens em seu processo de transformação da natureza. Pela primcira vez na história da humanidade. configura-sea /imitação estrutural do trabalho. A tendência da revolução microcletrônica, aliada às novas formas de gestão c organização, ao contrário das anteriores, é não expandir o mercado de trabalho do setor onde éimplantada e nem de qualquer outro. Isso significa que não há incorporação de mão-dc-obra na economia como um todo. Há um aumento brutal da produtividade sem geração de emprego. $\mathrm{Na}$ verdade, a tendênciaé a diminuição progressiva de postos de trabalho, tanto no curto como no longo prazo.

O trabalho. que já foi imposição nos primórdios do capitalismo, que é hoje um dircito reconhecido, corre o risco dese tornar um privilégio de poucos $\mathrm{em}$ um futuro muito próximo. Visões apocalípticas prevêem sociedades com ilhas de trabalhadores cercadas de multidões de famintos, fanáticos, drogados. O que poderia ser a realização do sonho da humanidade de acabar com todo o trabalho compulsório pode se tornar um pesadelo.

Uma outra possibilidade é repensar a sociedade. É procurar modos de distribuir a riqueza enão, necessariamente, passam pelo trabalho tradicional. É rever o significado de políticas sociais. É discutir novos papéis na sociedade. É, enfim, inventar uma outra forma de viver. Sem entretanto incorporar nesse processo a presença de trabalhadores. com sua visão de mundo que relaciona, de forma direta, tecnologia c qualidade de vida, scrá quase impossível enfrentar este desafio.

* Suzanna Sochaczewski é Doutoranda em Sociologia na CSP e Técnica do Dieese. 